\title{
PARTO COM ACOMPANHANTE E SEM ACOMPANHANTE: A OPINIÃO DAS PUÉRPERAS
}

Liana Mara Rocha Teles ${ }^{1}$, Hélcia Carla dos Santos Pitombeira ${ }^{2}$, Amanda Souza de Oliveira $^{3}$, Lydia Vieira Freitas ${ }^{4}$, Escolástica Rejane Ferreira Moura ${ }^{5}$, Ana Kelve de Castro Damasceno ${ }^{6}$

\begin{abstract}
RESUMO: Pesquisa de abordagem quantitativa, caráter descritivo e transversal, que teve como objetivo descrever as atividades desempenhadas pelo acompanhante durante o trabalho de parto e parto, além de comparar a experiência com acompanhante e sem acompanhante. Participaram 105 puérperas internadas entre setembro e outubro de 2008 com vivência anterior de parto sem acompanhante e vivência corrente de parto com acompanhante. Os dados foram coletados por meio de entrevista semiestruturada e processados no Statistical Package for the Social Sciences, com tratamento estatístico simples. Os resultados mostram que as principais atividades desenvolvidas pelos acompanhantes foram: presença constante; toque; verbalização de palavras de encorajamento; e massagens. Ao comparar as experiências, $81,9 \%$ consideraram melhor o parto atual, no qual a presença do acompanhante foi determinante para esta escolha em $46,6 \%$ dos casos. A experiência de estar com acompanhante durante o parto foi considerada positiva, reforçando a importância deste personagem no processo de parto.
\end{abstract}

PALAVRAS-CHAVE: Enfermagem; Parto humanizado; Acompanhantes de pacientes.

\section{CHILDBIRTH WITH AND WITHOUT A COMPANION: THE PUERPERAL VIEW}

ABSTRACT: Research of quantitative approach, descriptive and transversal study aimed to describe the activities performed by a companion during labor and delivery, as well as comparing the experience with and without the companion during labor. Participants were 105 postpartum women admitted between September and October 2008 with previous experience of childbirth unescorted and current experience of childbirth with a companion. Data were collected through a semistructured interview and processed in the Statistical Package for the Social Sciences with simple statistical treatment. The results show that the main activities developed by the companions were a constant presence, touch, verbalizing words of encouragement, and massages. By comparing the experiences, $81.9 \%$ considered best the present delivery, where the presence of the companion was decisive for this choice in $46.6 \%$ of cases. The experience of being accompanied during labor is positive reinforcing the importance of this character in the process of childbirth. KEYWORDS: Nursing; Humanized childbirth; Patient escort.

\section{PARTO CON ACOMPAÑANTE Y SIN ACOMPAÑANTE: LA OPINIÓN DE LAS PARTURIENTAS}

RESUMEN: Investigación de abordaje cuantitativo, carácter descriptivo y transversal, que tuvo como objetivo describir las actividades ejecutadas por el acompañante durante el trabajo de parto, además de comparar la experiencia con acompañante y sin acompañante. Participaron 105 parturientas internadas entre septiembre y octubre de 2008 con vivencia anterior de parto sin acompañante y vivencia corriente de parto con acompañante. Los datos fueron recogidos por medio de entrevista semiestructurada y procesados en Statistical Package for the Social Sciences con tratamiento estadístico simple. Los resultados muestran que las principales actividades desarrolladas por los acompañantes fueron: presencia constante; toque; verbalización de palabras para encorajar; y masajes. Al comparar las experiencias, $81,9 \%$ consideró mejor el parto actual, debido a la presencia del acompañante, que fue determinante en 46,6\% de los casos. La experiencia de ser acompañada durante el parto fue considerada positiva reforzando la importancia de ese individuo en el proceso de parto.

PALABRAS CLAVE: Enfermería; Parto humanizado; Acompañantes de pacientes.

${ }^{1}$ Enfermeira. Mestranda em Enfermagem pela Universidade Federal do Ceará-UFC.

${ }^{2}$ Enfermeira.

${ }^{3}$ Acadêmica de Enfermagem da UFC. Bolsista de Iniciação Científica-FUNCAP.

${ }^{4}$ Enfermeira. Mestranda em Enfermagem pela UFC. Bolsista FUNCAP.

${ }^{5}$ Enfermeira. Doutor em Enfermagem. Professor Adjunto do Departamento de Enfermagem da UFC. Pesquisador CNPq.

${ }^{6}$ Enfermeira. Doutor em Enfermagem. Professor Adjunto do Departamento de Enfermagem da UFC.

\section{Autor correspondente:}

Ana Kelve de Castro Damasceno

Universidade Federal do Ceará

R. Alexandre Baraúna, 1115 - 60430-160 - Fortaleza-CE_ Recebido: 24/01/10

E-mail: anakelve@hotmail.com

Aprovado: 04/11/10 


\section{INTRODUÇÃO}

Inicialmente, o parto era exercido por curandeiras, parteiras ou comadres, mulheres de confiança da gestante que, a partir de sua própria experiência, se tornaram familiarizadas com as manobras externas para facilitar o parto e com os eventos que acompanhavam a gravidez e o puerpério ${ }^{(1)}$.

Ao final do século XVI, com a utilização do fórceps pelo cirurgião inglês Peter Chamberlain, a profissão de parteira sofreu declínio. Esta nova técnica influenciou a aceitação da Obstetrícia como uma disciplina científica e dominada pelo homem, já que este poderia comandar o nascimento. O parto passou a ser visto como um evento perigoso, sendo importante a presença do médico. Desta forma, o uso do fórceps permitiu a intervenção masculina e a substituição do paradigma não intervencionista pela ideia do parto como um ato controlado pelo homem ${ }^{(2)}$.

Como consequência deste cenário, ocorreu a institucionalização do parto. As mulheres deixaram de parir em seus lares, no ambiente familiar, vivendo a ruptura dos hábitos de solidariedade feminina e do espaço da vida cotidiana. As práticas instituídas pelos hospitais, baseadas em normas e rotinas, tornaram as mulheres passivas durante o trabalho de parto e impossibilitaram a presença de pessoas de seu convívio social para apoiá-las neste momento ${ }^{(3)}$.

Nesse contexto, surge a necessidade de humanização do parto, recomendada pela Organização Mundial de Saúde (OMS) por meio do Projeto Maternidade Segura, criado em 1995, que preconiza um modelo de atenção ao parto e ao nascimento menos intervencionista e mais humanizado ${ }^{(4-5)}$. Dentre os princípios para a assistência humanizada, está a presença de um acompanhante durante o trabalho de parto, podendo ser este o companheiro da parturiente ou alguém da família.

Em 2005, como resultado de toda essa mobilização, foi aprovada, no Brasil, a Lei n. 11.108, que garante à parturiente o direito de ter a presença de um acompanhante durante o trabalho de parto, parto e pós-parto imediato, nas maternidades conveniadas ao Sistema Único de Saúde (SUS) ${ }^{(6)}$.

A presença de um acompanhante escolhido pela parturiente durante o processo de parto contribui significativamente para a prestação de apoio durante este. A presença do acompanhante proporciona bemestar físico e emocional à mulher e favorece uma boa evolução do período gravídico-puerperal. Além disso, o acompanhante passa segurança durante todo o processo parturitivo, o que pode diminuir as complicações na gestação, parto e puerpério, a utilização de analgesia, ocitocina, partos cesáreos e tempo de hospitalização do binômio mãe-filho ${ }^{(7)}$.

Apesar da evidente importância da figura do acompanhante durante o trabalho de parto, em algumas situações, a figura do acompanhante pode ser dispensável, a saber: opção da mulher por não ter um acompanhante, despreparo emocional do acompanhante escolhido ou desacato deste às normas da Instituição.

Frente à crença de que uma companhia intensiva e solícita no momento do parto pode minimizar receios e temores de mulheres que o vivenciam, surgiu o interesse de investigar como puérperas caracterizam a presença de um acompanhante no momento de seu parto. Para tanto, estabeleceu-se os seguintes objetivos: descrever as atividades desempenhadas pelo acompanhante durante o trabalho de parto, e parto e comparar a experiência de parto com acompanhante e sem acompanhante.

\section{METODOLOGIA}

Trata-se de um estudo descritivo, transversal, com abordagem quantitativa, realizado no período de setembro a outubro de 2008, com puérperas internadas em alojamento conjunto de maternidade escola de referência no Estado do Ceará.

A referida maternidade presta assistência à saúde em nível terciário e desenvolve atividades voltadas ao ensino, pesquisa e extensão, sendo também uma referência municipal e estadual para a prestação de cuidados à saúde de recém-nascidos e mulheres.

Participaram do estudo as puérperas internadas no período estabelecido para a coleta de dados (setembro a outubro de 2008); desse modo, contou-se com a participação de 105 mulheres. A coleta ocorreu no alojamento conjunto, um dia após o parto. A média de permanência dessas mulheres no setor é de dois dias, a depender da demanda de cuidados da mulher e do recém-nascido.

A fim de alcançar os objetivos da pesquisa, foram definidos os seguintes critérios de inclusão das participantes no estudo: vivência anterior de parto sem acompanhante e vivência atual de parto com acompanhante de escolha.

Os dados foram coletados por meio de entrevista semiestruturada que utilizou um formulário composto por 45 perguntas de múltipla escolha, abor- 
daram dados socioeconômicos, história obstétrica, perfil do acompanhante e avaliação da participação do acompanhante sobre: atitudes realizadas pelo acompanhante, grau de importância atribuído à presença do acompanhante, qualidades necessárias em um acompanhante, comparação entre o parto com acompanhante e parto(s) anterior(es) sem acompanhante. Os dados foram processados no Statistical Package for the Social Sciences (SPSS) versão 13.0 e receberam tratamento estatístico simples, com frequência absoluta e relativa.

$\mathrm{O}$ estudo obedeceu às normas da Resolução n. 196/96, do Conselho Nacional de Saúde (CNS), que trata de pesquisas envolvendo seres humanos ${ }^{(8)}$. As puérperas foram abordadas e esclarecidas quanto aos objetivos do estudo e convidadas a participar do mesmo. Após aceitação, deram sua anuência com o Termo de Consentimento Livre e Esclarecido. Houve aprovação do Comitê de Ética em Pesquisa da maternidade, sob o protocolo n.11/2008.

\section{RESULTADOS}

Observou-se que $88(83,8 \%)$ puérperas entrevistadas encontravam-se na faixa etária ideal para a concepção, ou seja, entre 20 e $35 \operatorname{anos}^{(9)}$. A maioria das mulheres, 92 (87,6\%), era proveniente da capital. Quanto ao nível de instrução, 56 (53,4\%), puérperas tinham baixa escolaridade (nível fundamental incompleto/ completo) e $82(78,0 \%)$ possuíam renda igual ou inferior a um salário mínimo. A maioria das mulheres, 91 (86,6\%), possuía companheiro fixo, estando casadas ou em união consensual.

Dos acompanhantes que se fizeram presentes durante o processo de parto, a maioria, $84(80 \%)$, pertencia ao sexo feminino e a categoria social de acompanhante mais frequente foi a mãe, com prevalência de 35 (33,4\%), seguida do esposo, com 20 (19,0\%). Em estudo semelhante, observou-se uma inversão na ordem de prevalência, no qual o companheiro representou $60,7 \%$ dos acompanhantes, seguido pela amiga $(16,1 \%)$, mãe $(12,5 \%)$ e irmã $(10,7 \%)^{(10)}$. Quanto ao perfil obstétrico dos acompanhantes pertencentes ao sexo feminino, 66 (78,5\% das acompanhantes mulheres) já haviam engravidado e vivenciado o parto.

A escolha do acompanhante se deu durante a gestação em 45 (42,8\%) mulheres, já em 49 (46,6\%), a escolha se deu na emergência, antes de dar entrada na sala de parto, pois não sabiam que era permitida a presença de um acompanhante durante o parto, nesta instituição. Cabe aqui, salientar a importância do processo de escolha do acompanhante, que deve acontecer durante a gestação e não no início do trabalho de parto, a parturiente dispondo, assim, de tempo para a escolha de uma pessoa com a qual a tenha intimidade e confiança suficientes para compartilhar este momento único.

Das mulheres entrevistadas, $10(9,5 \%)$ consideraram que o acompanhante não se envolveu ativamente no trabalho de parto, tendo uma presença passiva. Outras, 72 (68,5\%), afirmaram que o acompanhante proporcionava apoio emocional, mas não tinha conhecimento sobre técnicas para reduzir seus desconfortos físicos. Em contrapartida, 23 (22,0\%) puérperas consideraram que o acompanhante proporcionou tanto o apoio emocional quanto o físico. Temos que levar em consideração o fato de que a totalidade dos acompanhantes não participou de nenhuma atividade/ treinamento para que pudessem participar ativamente no processo de parto, fato esse que justifica a pequena parcela de gestantes que referiram ter recebido suporte físico do acompanhante.

Ao averiguar o grau de importância dado pelas puérperas à presença de um acompanhante durante o processo de parto, entre as 105 participantes, $87(82,8 \%)$ consideraram ser o acompanhante muito importante, $17(16,2 \%)$ julgaram ser importante e 1 $(1,0 \%)$ classificou-o como pouco importante.

Entre as atitudes dos acompanhantes, as mais prevalentes foram: presença constante para $105(100 \%)$, toque para $78(74,2 \%)$, verbalização de palavras de encorajamento para $90(85,7 \%)$ e massagens para $60(57,1 \%)$. As atividades realizadas pelo acompanhante foram agrupadas em quatro categorias: atitudes de apoio emocional, de apoio físico, de auxílio nas tarefas e de participação no parto (Tabela 1).

Tabela 1 - Distribuição das atividades realizadas pelo acompanhante durante o processo de parto segundo puérperas, no período de setembro a outubro de 2008 . Fortaleza, 2008

\begin{tabular}{lcc}
\hline Variáveis $(\mathbf{n}=\mathbf{1 0 5})$ & $\mathbf{N}$ & $\mathbf{\%}$ \\
\hline Apoio Emocional & & \\
Presença constante & 105 & 100 \\
Toque & 78 & 74,2 \\
Incentivou o parto normal & 90 & 85,7 \\
Rezou & 2 & 1,9 \\
Distraiu & 1 & 0,9 \\
Abraçou & 1 & 0,9 \\
\hline & & Continua
\end{tabular}


Continuação

\begin{tabular}{lcc}
\hline Variáveis (n= 105) & N & \% \\
\hline Apoio Físico & 60 & 57,1 \\
Realizou massagens & 9 & 8,5 \\
Proporcionou conforto & & \\
Auxílio nas tarefas & 8 & 7,6 \\
Ajudou ir ao banheiro/ banho & 2 & 1,9 \\
Ajudou a levantar da cama & 1 & 0,9 \\
Auxiliou na deambulação & & \\
Participação no parto/ pós-parto & 5 & 4,7 \\
Procurou remédio/ajuda & 3 & 2,8 \\
Trouxe o recém-nascido para mamar & 3 & 2,8 \\
Cortou o cordão umbilical & 1 & 0,9 \\
Percebeu que o bebê estava nascendo & 1 & 0,9 \\
Fotografou & & \\
\hline
\end{tabular}

Ao solicitar à mulher que fizesse uma comparação entre o parto atual e o parto anterior (Tabela 2), 86 (81,9\%) mulheres consideraram ser melhor o parto atual, enfatizando diferentes motivos como a companhia de alguém de confiança, o acolhimento e assistência por parte dos profissionais, a organização do ambiente, a rapidez do parto e diminuição das dores. Em contrapartida, 14 (13,3\%) puérperas consideraram melhor o parto anterior devido à maior rapidez, por este ter sido menos doloroso e por ter recebido maior assistência profissional. $\mathrm{O}(\mathrm{s})$ parto(s) anterior(es) e o atual foram considerados igualmente bons por $7(6,6 \%)$ mulheres.

Tabela 2 - Comparação entre a experiência de parto anterior e atual segundo puérperas da MEAC no período de setembro a outubro de 2008. Fortaleza, 2008

\begin{tabular}{lcc}
\hline Variáveis & N & \% \\
\hline Parto atual melhor & 49 & 46,6 \\
Presença do acompanhante & 22 & 20,9 \\
Acolhimento/ assistência profissional & 8 & 7,6 \\
Organização do ambiente & 9 & 8,7 \\
Menos demorado & 4 & 3,8 \\
Menos doloroso & & \\
Parto anterior melhor & 7 & 6,6 \\
Menos doloroso & 7 & 6,6 \\
Menos demorado & 2 & 1,9 \\
Melhor assistência profissional & & \\
\hline
\end{tabular}

Quanto à pretensão de serem acompanhadas novamente em um próximo parto, 104 (99,0\%) mulheres responderam que sim, indo ao encontro da importância que a maior parte destas mulheres atri- buiu à presença do acompanhante durante o parto.

\section{DISCUSSÃO}

As atividades de apoio variam de acordo com as necessidades, desejo e cultura da mulher ${ }^{(11)}$. Outros autores acrescentam que as ações desempenhadas pelos acompanhantes são tão importantes durante o trabalho de parto e o parto quanto os cuidados obstétricos profissionais propriamente ditos ${ }^{(12)}$.

Nesta pesquisa, percebemos que as atividades que envolvem apoio emocional foram as mais frequentes entre os acompanhantes. Dentre os núcleos de sentido na postura e prática dos acompanhantes está "dar força", "ficar junto/ao lado" e "observar tudo"(10), atitudes representadas nesse estudo por meio da presença constante, toque e incentivo ao parto normal. Corroborando este achado, em estudo semelhante, verificou-se que dentre as atividades mais frequentes realizadas pelos 56 acompanhantes foram de apoio emocional como permanecer ao lado segurando a mão $(71,4 \%)$ e encorajamento no período expulsivo $(46,4 \%)^{(13)}$.

Muitos acompanhantes também transmitiram apoio físico, por meio de medidas de conforto como massagens, minimização do calor e auxílio nos exercícios pélvicos. Tal achado ratifica o relato das puérperas que afirmaram ter a presença do acompanhante contribuído para o alívio das dores durante o parto.

O auxílio nas tarefas também foi uma das maneiras de contribuição do acompanhante, sendo "ir ao banheiro" e "auxílio no banho" as tarefas mais desempenhadas pelo acompanhante. As dores e o medo que acompanham a mulher no período de parto, muitas vezes, impedem que elas realizem atividades que exijam maior esforço físico, sem o auxílio de uma pessoa.

Nesse estudo, poucos acompanhantes tiveram participação ativa no trabalho de parto. A participação ativa foi representada por: procura por remédios/ ajuda e percepção da proximidade do parto por meio da visualização do recém-nascido no canal vaginal. Tais atitudes são favoráveis ao passo que transmitem à mulher uma certeza de proteção e auxílio, contribuindo para minimizar os sentimentos negativos presentes durante o período.

Para uma participação ativa no processo de parto é necessário conhecimento e iniciativa por parte do acompanhante, bem como adequado acolhimento por parte dos profissionais de saúde inseridos na sala 
de parto, o que promove real inserção do acompanhante no processo de parto.

Estudo caso-controle verificou que mulheres acompanhadas durante o parto amamentaram por mais tempo e com intervalos mais flexíveis. Tal achado pode estar associado à promoção precoce do aleitamento materno pelo acompanhante e favorecimento do vínculo mãe-filho ${ }^{(14)}$. No presente estudo, tal atitude foi facilitada por três $(3,7 \%)$ dos acompanhantes.

Entre os acompanhantes, três $(2,8 \%)$ realizaram o corte do cordão umbilical. Vale ressaltar que o corte do cordão umbilical pelo acompanhante não era sugerido nas opções disponíveis no instrumento, sendo um fato destacado pelas puérperas que receberam este cuidado. Em outro estudo, o corte do cordão umbilical foi realizado por $35(62,5 \%)$ dos 56 acompanhantes, tendo tal aspecto sido considerado como uma prática de grande relevância para a integração familiar, já que o ato de cortar o cordão umbilical, realizado pelo acompanhante, confere um significado de participação em um rito de passagem que é o nascimento ${ }^{(13)}$.

A vivência do parto é a única fonte de conhecimento próprio do processo do parto, sendo o modo de sentí-la processado por meio da comparação com partos anteriores, estando o medo quase sempre presente, não importando o número de experiências passadas, e sendo este fortalecido pela vivência de experiências negativas ${ }^{(15)}$.

A presença do acompanhante foi trazida como um dos fatores determinantes para uma melhor vivência do período de parto por $49(46,6 \%)$ mulheres. O suporte de alguém de confiança traz diversos benefícios à mulher, sendo estes percebidos principalmente no que se refere à saúde materna: redução da taxa de cesariana; diminuição do uso de ocitocina, do tempo do trabalho de parto, do uso de fármacos para o alívio da dor; e uma elevação da realização materna no que se refere ao nascimento do filho ${ }^{(16)}$.

Outro fator que merece destaque é o acolhimento concedido pelos profissionais e a humanização do serviço, sendo isto ressaltado por $22(20,9 \%) \mathrm{mu}-$ lheres como um dos fatores determinantes para tornar o último parto melhor que os demais.

Cabe aqui salientar que, apesar de grande importância, a presença do acompanhante não é suficiente para garantir a humanização do parto, entre outros determinantes, está a adoção de uma postura humanizada por parte dos profissionais que atuam junto à parturiente, proporcionando a esta um cuidado holístico, contemplando os aspectos biopsicossociais.
O bom desenvolvimento do trabalho de parto está intimamente relacionado ao bem-estar físico e emocional da mulher e, para isso, se faz necessário o respeito ao direito da mulher a privacidade, segurança e conforto. Nesse sentido, a organização do ambiente foi um aspecto enfatizado por $8(7,6 \%)$ mulheres. A maternidade em estudo inaugurou, em 11 de julho de 2007, seu Centro de Parto Humanizado (CPH), sendo pioneira no Brasil em acolher a mulher gestante em apartamento individual.

Ao comparar o parto atual com o(s) anterior (es), 9 (8,7\%) mulheres enfatizaram ter havido uma redução na frequência e intensidade das contrações e $4(3,8 \%)$ relataram uma diminuição do tempo de trabalho de parto.

As variáveis "duração do trabalho de parto" e "uso de analgesia/medicamentos para alívio da dor" foram avaliadas em oito ensaios clínicos. Em três deles, ambas as variáveis apresentaram redução no grupo de intervenção, isto é, nas parturientes que receberam suporte, tendo sido a redução na duração do trabalho de parto mais frequente nos estudos em que o suporte foi provido por mulheres leigas, sem treinamento, e por doulas ${ }^{(3)}$. Estudo realizado na Maternidade Escola do Paraná acerca de técnicas de cuidados não farmacológicos para o alívio da dor, verificou a importância do acompanhante familiar para o auxílio na deambulação, técnica que ajudou no alívio da dor referida pelas parturientes ${ }^{(17)}$.

O parto é um evento único e, a cada vivência, traz características clínicas próprias que contribuem ou não para sua facilitação. Das puérperas, 14 (13,3\%) consideraram melhor o parto anterior, tendo entre as justificativas: menor período de tempo em que este ocorreu, contrações dolorosas menos intensas e melhor assistência profissional.

Além da presença do acompanhante, 60 $(57,1 \%)$ mulheres contaram com o apoio das doulas durante o parto. $\mathrm{O}$ termo doula $($ do grego $=$ mulher que serve) começou a ser utilizado na América do Norte para denominar mulheres com um treinamento especial em dar suporte durante o parto, sendo também conhecidas como acompanhantes de trabalho de parto, acompanhantes de parto e assistentes de trabalho de parto ${ }^{(18)}$. Trata-se de uma mulher sem experiência técnica na área da saúde, que orienta e assiste a nova mãe no parto e nos cuidados com o bebê, e para isso recebe treinamentos específicos oferecidos pela instituição na qual desempenham tal atividade, contribuindo positivamente no processo de parto. 


\section{CONSIDERAÇÕES FINAIS}

Com a institucionalização do processo reprodutivo, a mulher adquiriu o acesso à tecnologia $\mathrm{e}$ ao atendimento por um profissional qualificado, no entanto, a tecnologia e a humanização são práticas que nem sempre estão aliadas durante a prestação do cuidado à parturiente. Por isso, nas últimas décadas, vem acontecendo uma mobilização mundial em prol da humanização do parto.

No Brasil, diversas políticas vêm promovendo uma assistência integral e humanizada à mulher, sendo a presença do acompanhante junto à parturiente um avanço no processo de parturição.

As principais atividades realizadas pelo acompanhante foram aquelas de apoio emocional, tendo sido limitado o apoio físico fornecido por estes. Enfatiza-se a necessidade de dar aos acompanhantes condições para desempenhar um papel de apoio e participação ativa, por meio de técnicas educativas específicas para este público-alvo - oficinas, manuais, entre outras estratégias, de forma a ampliar sua capacidade de cuidado e prestação de apoio.

Ao comparar as experiências de parto, grande parte mulheres consideraram ser melhor o parto atual, sendo a presença do acompanhante fator determinante para esta escolha, em algumas ocasiões. Assim, podemos concluir que a experiência de ser acompanhada durante o parto foi considerada positiva pela quase totalidade das puérperas, reforçando a importância deste personagem no processo de parto.

Também ficou evidenciada a humanização dos profissionais da instituição em estudo na assistência ao parto, assim como a contribuição positiva de um ambiente acolhedor e organizado para uma melhor vivência deste período.

As realizações de novos estudos desta natureza contribuirão para a implantação da atual legislação em vigor no Brasil nas demais maternidades do Ceará, permitindo que todas as parturientes, independentemente do seu nível socioeconômico e cultural, tenham o apoio de uma pessoa de sua escolha durante todo o processo de parto. Também recomendamos a realização de novas pesquisas que enfoquem a percepção da mulher frente à presença de um acompanhante durante o parto, visto que a maior parte dos estudos publicados enfatiza apenas a opinião dos profissionais e acompanhantes sobre este fato.

\section{REFERÊNCIAS}

1. Nagahama EEI, Santiago SM. A institucionalização médica do parto no Brasil. Cienc Saúde Colet. 2005;10(3):651-9.

2. Osava RH, Mamede MV. A assistência ao parto ontem e hoje: a representação social do parto. J Bras Ginecol. 1995;105(1/2):3-9.

3. Brüggeman OM, Parpinelli MA, Osis MJD. Evidências sobre o suporte durante o trabalho de parto e parto: uma revisão de literatura. Cad Saúde Pública. 2005;21(5):1316-27.

4. World Health Organization. Regional Office for Europe. Joint Interregional Conference on Appropriate Technology for Birth [internet]. 1985. [acesso em 2009 mar 15]. Disponível: http://www.choicesinchildbirth. org/who.htm.

5. World Health Organization. Care in normal birth: a practical guide. Maternal and newborn health - safe motherhood unit. Geneva: WHO; 1996.

6. Ministério da Saúde (BR). Portaria n. 2418 de 02 de dezembro de 2005. Regulamenta, em conformidade com o art. $1^{\circ}$ da Lei n. 11.108, de 7 de abril de 2005, a presença de acompanhante para mulheres em trabalho de parto, parto e pós-parto imediato nos hospitais públicos e conveniados com o Sistema Único de Saúde - SUS. Diário Oficial da República Federativa do Brasil, 06 Dez. 2005. Seção 1: 32.

7. Bruggemann OM, Osis MJD, Parpinelli MA. Apoio no nascimento: percepções de profissionais e acompanhantes escolhidos pela mulher. Rev Saúde Pública. 2007;41(1):44-52.

8. Ministério da Saúde (BR). Conselho Nacional de Saúde. Diretrizes e normas regulamentadoras de pesquisa envolvendo seres humanos. Resolução n. 196, de 10 de outubro de 1996. Brasília(DF); 1996.

9. Ministério da Saúde (BR). Secretaria de Políticas de Saúde. Departamento de Gestão de Políticas Estratégicas. Área Técnica da Saúde da Mulher. Gestação de alto risco. Manual técnico. Brasília, 2000.

10. Nakano AMS, Silva LA, Beleza ACS, Stefanello J, Gomes FA. O suporte durante o processo de parturição: a visão do acompanhante. Acta Paul Enferm. 2007;20(2):131-7.

11. Hodnett ED, Lowe NK, Hannah ME, Willan AR, Stevens B, Weston JA, et al. Effectiveness of nurses as providers of birth labor support in North American 
hospitals: a randomized controlled trial. JAMA. 2002;288(11):1373-81.

12. Enkin M, Keirse MJNC, Renfrew M, Nielson J. Effective care in pregnancy and childbirth. Oxford: Oxford University Press; 1995.

13. Pinto CMS, Basile ALOB, Silva SF, Hoga LAK. Acompanhante no parto: atividades desenvolvidas e avaliação da experiência. REME: Rev Min Enferm. 2003;7(1):41-7.

14. Hofmeyer G, Nikodem VC, Wolman WL. Companionship to modify the clinical birth environment: effects on progress and perceptions of labour and breast feeding. Br J Obstet Gynaecol. 1991;98(8):756-64.

15. Oliveira ME, Zampieri MFM, Bruggemann OM. A melodia da humanização: reflexões sobre o cuidado no processo de nascimento. Florianópolis (SC): Cidade Futura; 2001.

16. Zhang J, Bernasko JW, Leybovich E, Fahs M, Hatch MC. Continuous labor support from attendant for primiparous women: a meta-analysis. Obstet Gynecol. 1996;88(4 Pt. 2):739-44.

17. Sescato AC, Souza SRRK, Wall ML. Os cuidados não-farmacológicos para alívio da dor no trabalho de parto: orientações da equipe de enfermagem. Cogitare Enferm. 2008;13(4): 585-90.

18. Hodnett ED, Gates S, Hofmeyer GJ, Sakala C. Continuous support for women during childbirth (Cochrane Review). In: The Cochrane Library. Oxford: Update Software; 2005. 